\title{
IMPLEMENTAR ESTRATEGIAS PARTICIPATIVAS DE CREACIÓN DE EMPRESAS DE BASE TECNOLÓGICA DE PRODUCCIÓN Y COMERCIALIZACIÓN, FUNDAMENTADAS EN EL TRABAJO ASOCIATIVO PARTICIPATIVO
}

\section{IMPLEMENT PARTICIPATORY STRATEGIES FOR THE CREATION OF TECHNOLOGY-BASED PRODUCTION AND MARKETING COMPANIES, BASED ON PARTICIPATORY ASSOCIATIVE WORK}

Autor 1. Lucía Salgado González

Investigador Principal

https://orcid.org/0000-0002-2586-8389

Correo electrónico: lucia.salgado@unad.edu.co

Autor 2: Ana Claudia Toribio Martínez

Coinvestigador_Estudiante

https://orcid.org/0000-0002-8669-2700

Correo electrónico: martineztoribioana@gmail.com

UNAD CCAV SAHAGUN

Semillero ECOSPROG

Grupo de Investigación INCACEN

\section{RESUMEN}

La presente investigación se ubica en el contexto del desarrollo local en el municipio de San Andrés de Sotavento en el departamento de Córdoba, cuyo objetivo es Establecer estrategias participativas de creación de empresas de base tecnológica de producción y comercialización, fundamentadas en el trabajo asociativo participativo. Para ello se emplea la metodología ZOPP (por sus siglas en alemán Ziel-Orientierte Projekt-Planung, en español Planeación de Proyectos Orientada a Objetivos). Esta estrategia participativa permite identificar la problemática común de la población de san Andrés de sotavento, tomando como base el trabajo realizado por 30 mujeres cabeza de hogar que tienen a su cargo el sustento de sus familias, para estudiar posibles soluciones a la difícil y precaria situación económica a la que se ven abocadas para sacar adelante a sus familias, para ello se realizaron 6 talleres participativos en las instalaciones del auditorio municipal.Las estrategias de solución a la problemática vigente se encuentran en los siete (7) ejes rectores, etapas 0 fase del desarrollo del proyecto así: Revisión de fuentes secundarias, Información de las fuentes primarias, Identificación de factores de cambio, Selección de las variables estratégicas, juego de actores, análisis de encuestas, diseño de estrategias. Con el fin de lograr el empoderamiento sobre los temas de asociatividad, estrategias participativas de creación de empresas de base tecnológica de producción y comercialización y trabajo asociativo participativo. 



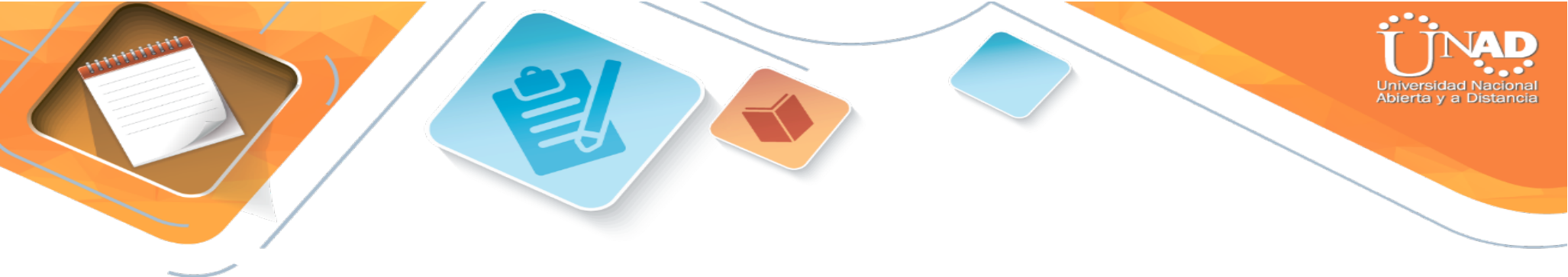

fin de lograr que un grupo focalizado de la población, madres cabeza de hogar logren insertarse en procesos de construcción de economía familiar, aprovechando los recursos de su entorno y los conocimientos ancestrales para mejorar las técnicas de producción y comercialización de sus productos, para lo cual se realiza talleres que permitan apropiarse de los conocimientos necesarios para asociarse y construir colaborativamente empresas.

\section{FORMULACIÓN DEL PROBLEMA}

¿Cuáles son las estrategias participativas que se deben implementar para la creación de empresas de base tecnológica de producción y comercialización, fundamentadas en el trabajo asociativo participativo?

\section{OBJETIVOS}

Implementar estrategias participativas de creación de empresas de base tecnológica de producción y comercialización, fundamentadas en el trabajo asociativo participativo en el Municipio de San Andrés de Sotavento.

\section{OBJETIVOS ESPECÍFICOS}

Realizar diagnóstico participativo con la comunidad del municipio de San Andrés de Sotavento para verificar en qué estado se encuentran los programas de producción agrícola de base tecnológica para su comercialización y de qué manera se involucra a las madres cabeza de hogar.

Identificar acciones orientadas al empoderamiento en las mujeres cabeza de hogar del municipio de San Andrés de Sotavento para la creación de empresas de base tecnológica de producción y comercialización, fundamentadas en el trabajo asociativo participativo.

Capacitar a la comunidad de mujeres cabeza de hogar sobre los temas de asociatividad, espíritu empresarial, liderazgo, creación de empresas de base tecnológica.

Realizar la sistematización del proceso de investigación para la realización de la creación de una empresa asociativa de base tecnológica, como segunda fase del proyecto.

\section{METODOLOGÍA}

\section{Tipo de estudio:}

El tipo de estudio que se utilizará es el Exploratorio-formulativo.

\section{Métodos:}

El método de investigación será deductivo-cuantitativo.

\section{Población y Muestra:}

El municipio de San Andrés de Sotavento cuenta con una población de 45.006 habitantes, pero no se tiene un dato preciso de la población de mujeres cabeza de hogar, para lo cual se identificó un número de 30 mujeres para el desarrollo del proyecto. 


Alcaldía de San Andrés. Plan de Desarrollo Municipal "El comienzo es progreso". (2016 2019).

Recuperado

de

http://sanandressantander.micolombiadigital.gov.co/sites/sanandressantander/conte nt/files/000007/336_plan-de-desarrollo-comienza-el-progreso-2016--2019.pdf

Baez L., L. (2010). Guía para el Desarrollo y Fortalecimiento de Organizaciones Empresariales Rurales, 62. $\quad$ Recuperado de http://unpan1.un.org/intradoc/groups/public/documents/icap/unpan049902.pdf

Convenio Administrativo (2913). No. M-923 de 2013 celebrado entre la Nación, Ministerio del Interior, y el Cabildo Mayor Regional del Pueblo Zenú. Diagnostico Comunitario y Líneas de Acción para el Plan de Salvaguarda étnica del pueblo Zenú capitulo Córdoba-Sucre y dispersos. (2014). Recuperado de https://siic.mininterior.gov.co/sites/default/files/pueblo_zenu__diagnostico_comunitario_tomo_1.pdf

Corradine, M. Resguardo Indigena Zenu De San Andres de Sotavento Tradicion Artesanal de la Tejeduria En Cañaflecha. (2013). Recuperado dehttps://repositorio.artesaniasdecolombia.com.co/bitstream/001/1797/1/INSTD\%20 2013.\%2043.pdf

Departamento Administrativo Nacional de Estadística - DANE. (2016). Tercer censo nacional agropecuario: Hay campo para todos - Tomo 2. Recuperado dehttps://www.dane.gov.co/files/images/foros/foro-de-entrega-de-resultados-ycierre-3-censo-nacional-agropecuario/CNATomo2-Resultados.pdf

Departamento Nacional de Planeación - DNP. (n.d.). Lineamientos de política pública para la asociatividad rural en Colombia "Rutas para la Asociatividad Rural." Recuperado de https://www.dnp.gov.co/programas/agricultura/Paginas/Rutas-para-laasociatividadrural-en-Colombia.aspx

Fernández, J. (s.f.). Planificación de Proyectos Orientado a Objetivos: el Método Zopp. Recuperado http://revistas.ucm.es/index.php/CUTS/article/viewFile/CUTS8989110115A/8637

Instituto Interamericano de Cooperación para la Agricultura. Diseño e implementación de la estrategia de Desarrollo Rural del Departamento del Cesar. (2004). Recuperado de https://books.google.com.co/books?id=5KiCX9ax9FAC

República de Colombia, Ministerio de Cultura. Zenú, la gente de la palabra. (s.f.). Recuperado http://www.mincultura.gov.co/areas/poblaciones/noticias/Documents/Caracterizaci\% C3\%B3n\%20del\%20pueblo\%20Zen\%C3\%BA.pdf

Terrones, A. (2013). El Colegio Mexiquense, A.C. Toluca, México. Planeación participativa para elaborar un plan de desarrollo municipal: el caso de Acaxochitlán, Hidalgo. Economía, Sociedad y Territorio, XIII(42), 521-559. Recuperado de https://www.redalyc.org/pdf/111/11126608008.pdf 